\title{
LAGRANGIAN VELOCITY PROFILES IN THE WAKE OF A HIGH SPEED VESSEL
}

\author{
L. Meadows,${ }^{*}$ G. Meadows,${ }^{*}$ A. Troesch,${ }^{*}$ S. Cohen,${ }^{*}$ K. P. Beier,${ }^{*}$ \\ G. Root, ${ }^{*}$ O. M. Griffin $\dagger$ and T. F. Swean JR $\dagger$ \\ * Department of Naval Architecture and Marine Engineering, University of Michigan, Ann Arbor. \\ Michigan, U.S.A.; †Naval Research Laboratory, Washington, D.C., U.S.A.
}

\begin{abstract}
A video imaging technique is employed in a towing basin to obtain high resolution surface Lagrangian velocity observations in the centerline wake region of a high speed, twin screw surface vessel. Approximately 30,000 surface velocity realizations within the wake region extending from the stern to approximately six model ship lengths aft are used for comparison with both recent full-scale and numerical model results. Analysis of this data set reveals spatial decay rates in the mean and fluctuating velocity components which serve to identify relevant scales of motion and define candidate mechanisms for the persistence of these wakes in remotely sensed ocean surface data.
\end{abstract}

\section{INTRODUCTION}

Much Is still unknown and there continues to be a lack of consensus concerning the physics of the remote sensing of ship wakes. The true surface flow in the wake of a self-propelled body is a manifestation of the flow below the surface. The flow in the wake is extremely complex, being a superposition (often non-linear) of turbulent shear flows, coherent vortex flows, free surface waves, bubble flows and potentially internal waves (Reed et al., 1990; Meadows et al., 1990).

One of the most observable features in the wake of a surface ship is the long, narrow region of relatively calm water that extends aft of the ship. This "dead water" or centerline wake region is typically two to four ship beams in width and, depending on the sea state and the ship speed, persists for upwards of many tens of ship lengths aft. The near-field centerline surface wake is a composite of the various contributions from the individual flows above and interactions between them. Recent work related to the present study has focused on the modification of the ocean and ship generated waves by the mean surface flow (Griffin et al., 1989) and on the ensuing variations in the radar contrast signature over the wake (Skop et al., 1989).

The purpose of this investigation was to provide surface Lagrangian velocity profiles in the near wake region of a high speed twin screw vessel. Two-dimensional viscous wake velocity profiles at the free surface were desired from the stern of the vessel to as many ship lengths aft as was feasible within the constraints and limitations of the test basin. The "downstream" rates of decay of both the transverse and longitudinal velocity components were of primary interest for numerical model verification and to provide an experimental foundation upon which to guide full-scale measurement efforts. This research activity was initiated through a desire to obtain greater knowledge of the complex hydrodynamics in operation in the viscous wake region of modern surface 
ships and how these interactions at the free surface may affect active remote sensing of the ocean. An example of an airborne Synthetic Aperture Radar (SAR) image of a dark centerline wake is provided in Fig. 1. The image size is approximately $4.5 \times 7 \mathrm{~km}$ and provides both an $X$ - and $L$-band, simultaneously obtained, optically processed view of the sea surface return at $3 \times 3 \mathrm{~m}$ resolution.

The Digital Automated Radar Tracking System (DARTS) (Meadows et al., 1988) was utilized to provide surface Lagrangian velocity profiles in the viscous wake tegion. The velocity analysis utilized hardware and software developed in conjunction with DARTS to acquire trajectories of tag particles seeded in the near wake region of a towed ship model. For this application, the radar portion of the DARTS system was replaced by a conventional high resolution video camera system. Video images were digitized and examined for each particle location and surface velocities were calculated, with successive data runs compiled in a statistical framework. As a result of this investigation, nearly 30,000 velocity observations were obtained in the viscous wake region from immediately astern of the transom to approximately five ship lengths downstream. Although towed in the Ship Hydrodynamics Test Facility, University of Michigan, the vessel propeller loadings were adjusted to simulate a self-propelled vessel. Only the twin screwed, outboard rotation data runs have been analyzed in detail and compiled in this summary, although wake fraction survey coverage cxists for single screw as well as no propeller operation cases.

\section{EXPERIMENTAL CONFIGURATION}

The purpose of this test was to optically track tagged particles dropped at known locations in the surface wake. A schematic representation of the test apparatus is provided in Fig. 2. The dropper simultaneously places 15 targets on the free surface at $5 \mathrm{~cm}$ intervals normal to the direction of model travel. Longitudinal as well as transverse offsets of the target dropper were utilized to acquire complete coverage of the wake region of interest. The targets used were luminous polyethylene disks, $6 \mathrm{~mm}$ in diameter and $1.5 \mathrm{~mm}$ thick and were slightly buoyant to provide a true representation of the surface velocity.

The model used for these tests, DTRC (David Taylor Research Center) No. 5369 1 , is a 1:25 scale model of a high speed twin screw vessel with a model length of $7.57 \mathrm{~m}$ and a beam of $0.67 \mathrm{~m}$. The narrow beam of this vessel necessitated the placement of the starboard engine room aft of the port engine room. This geometry resulted in a shallower inclination angle of the port propeller shaft. The model appropriately displays this cross-ship asymmetry.

The Ship Hydrodynamic Tow Tank is $109.7 \mathrm{~m}$ long. $6.7 \mathrm{~m}$ wide and $3.05 \mathrm{~m}$ deep. Mounted on rails over the tank are the main carriage and subcarriage which serve to transport data acquisition and analysis devices, ship models and personnel at speeds from 0.076 to $6.084 \mathrm{~m} / \mathrm{sec}$ at an accuracy of $0.006 \mathrm{~m} / \mathrm{sec}$. This test series was run at the design displacement for one speed, $20 \mathrm{kn}$. $(10.3 \mathrm{~m} / \mathrm{sec})$ full-scale.

The test section of the model basin was darkened and illumination of the targets was provided by an array of ultra-violet fluorescent lights. A Pulnex model TM-540 high resolution nadir viewing video camera was mounted approximately $4 \mathrm{~m}$ above the water surface on the dropper centerline.

Data runs were taken with the target dropper on centerline and one-half model 


\section{SHIP WAKES}

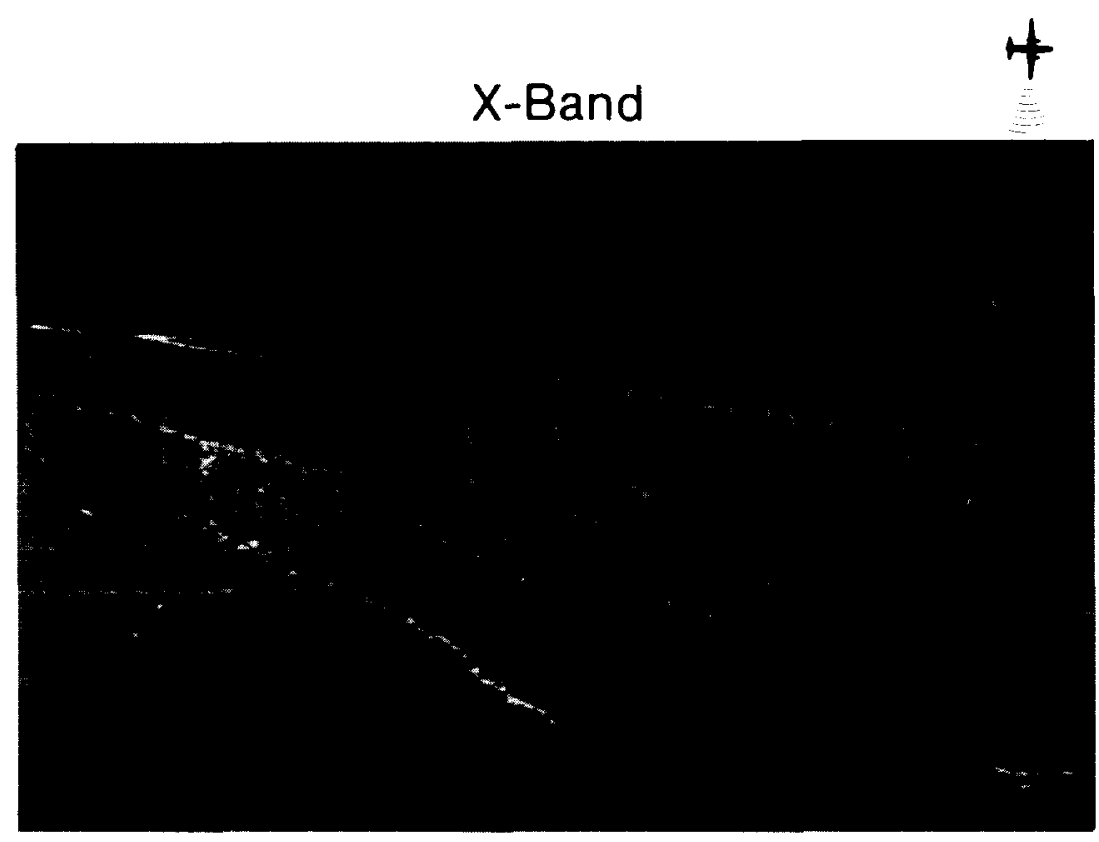

\section{L-Band}

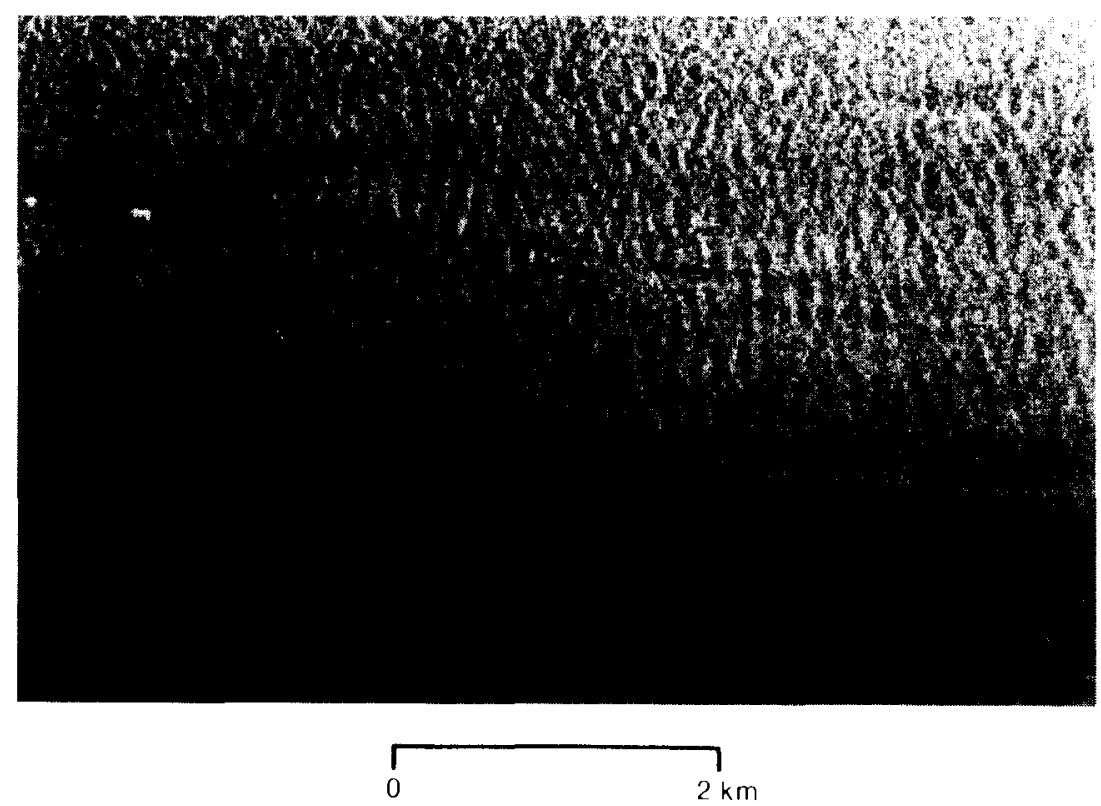

FIG. 1. Simultaneous, $X$-and $L$-band, airborne, synthetic aperture radar image of dark centerline ship wake 


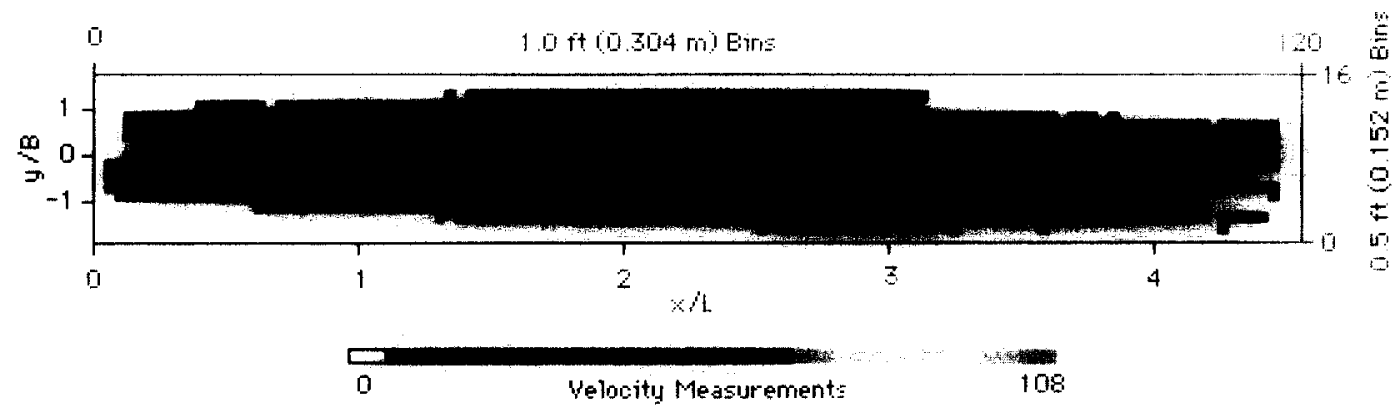

Fig. 5. Velocity measurement point density by bin location.
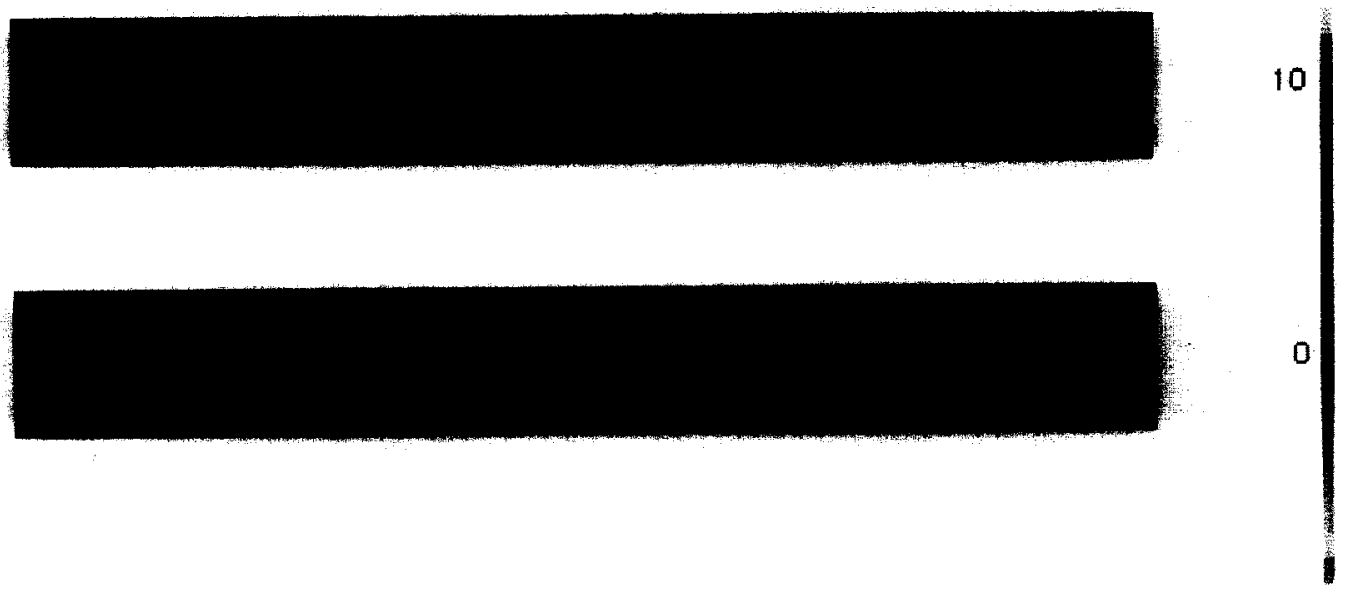

$-10$

Fig. 8. Resultant contour image showing $W_{x} / W_{y}$ superposition after light filtering $\left(\omega_{x}=0.35, l_{2}=5\right.$. $\left.\omega_{y}=0.45, L_{y}=4\right)$.

FIG. 9. Resultant contour image showing $W_{x} / W_{y}$ superposition after light filtering $\left(\omega_{x}=0.35, L_{\mathrm{c}}=5\right.$. $\left.\omega_{v}=0.45, L_{y}=4\right)$. 
Surfoce Woke: Direction and Mognitude

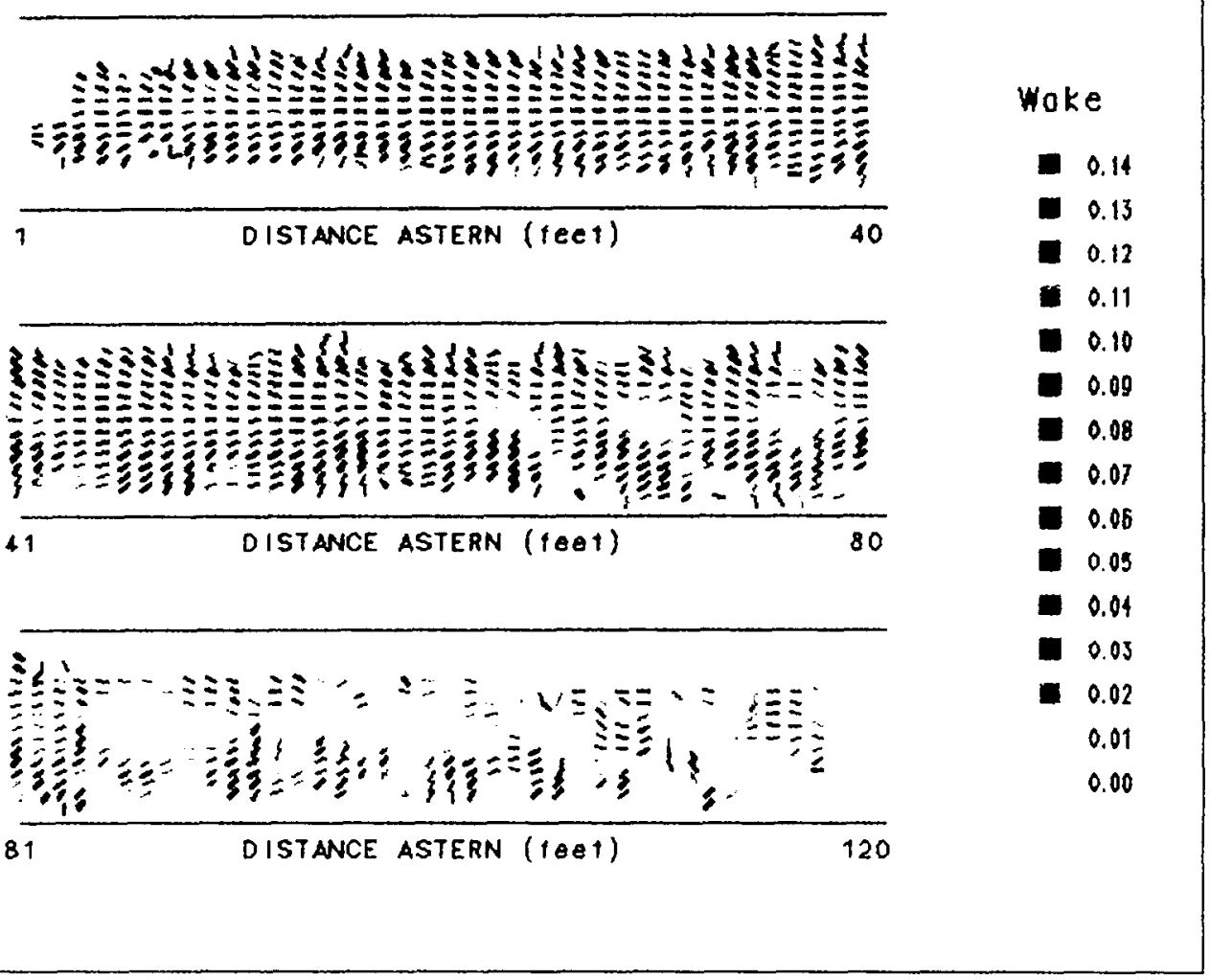

Fic. 14. Vector diagram of lightly filtered surface wake fraction. 



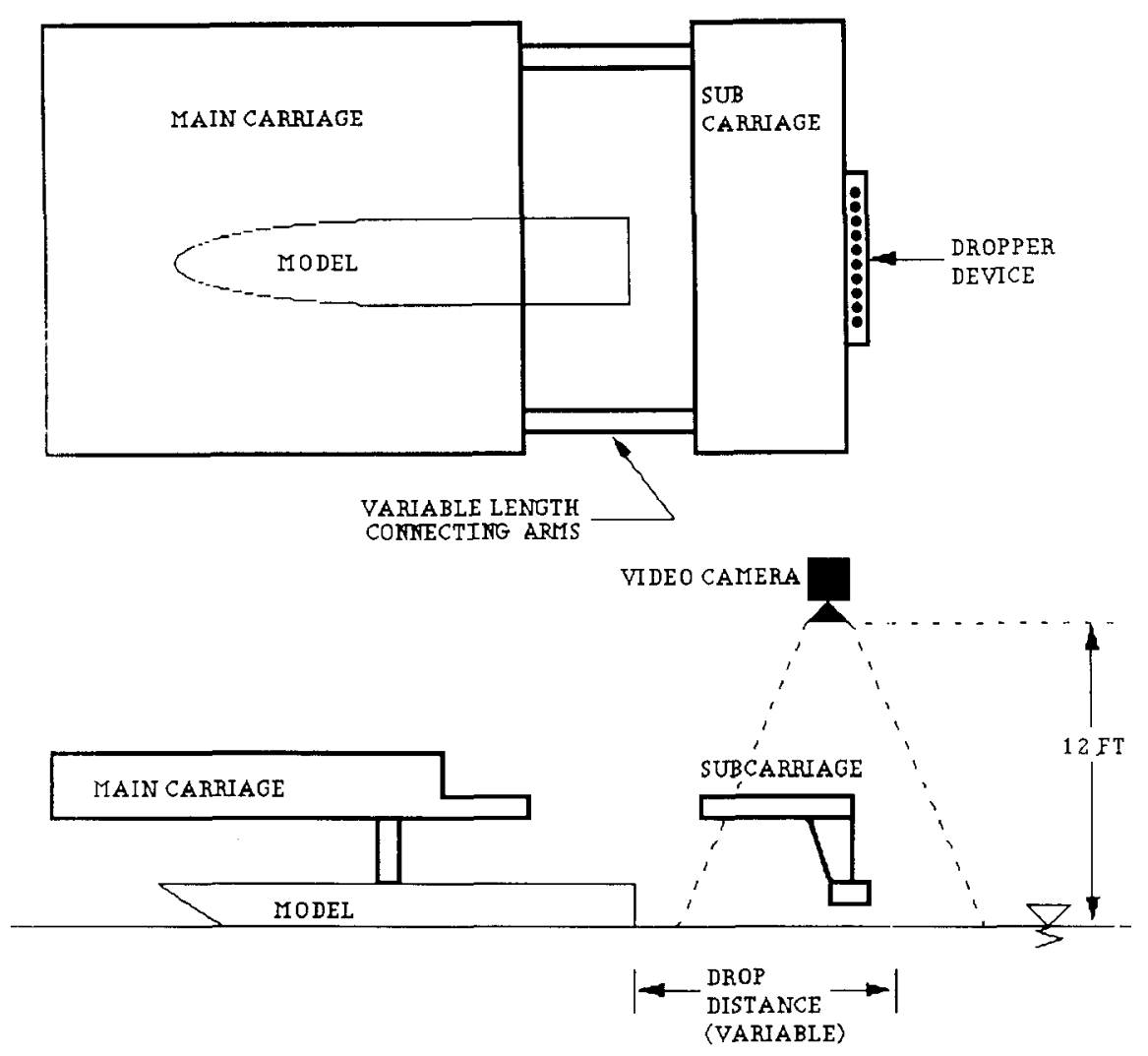

FIG. 2. Schematic representation of test apparatus.

beam to port and starboard at six distances aft for both standard and trail shaft conditions. Figure 3 provides a schematic representation of the region of wake coverage. Each configuration was run a minimum of five times to indicate the level of data repeatability. Table 1 provides a summary of the test matrix.

Individual data runs were recorded for varying lengths of time depending on the length of time it took for the targets to migrate out of the field-of-view. No runs exceeded $60 \mathrm{sec}$ and 20-30 sec was typical. A "zero drift" was taken for 1 min before each series of runs to verify still water conditions in the tow tank facility. For the zero

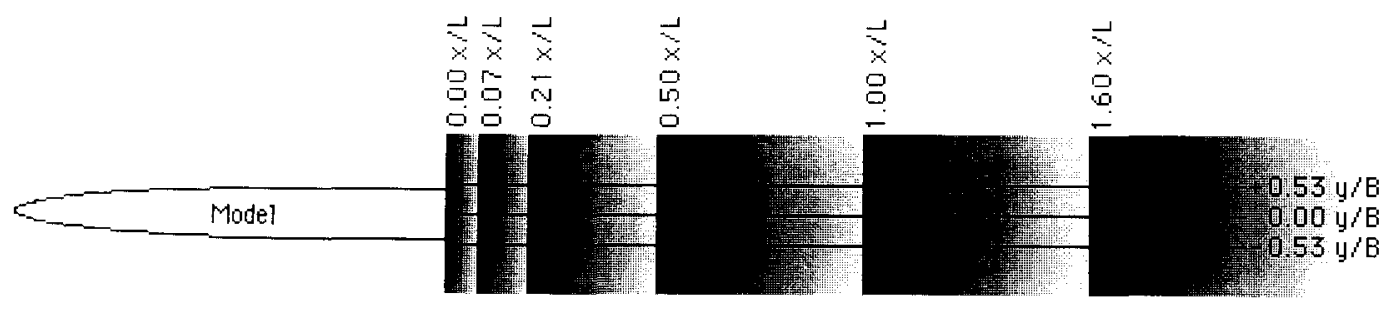

FIG. 3. Wake coverage showing longitudinal and transverse offsets of target dropper. 
TABLE 1. Test Matrix SUMmary, NUMber OF REPETITIVE RUNS FOR EACH CONFIGURATIOA

\begin{tabular}{|c|c|c|c|c|c|c|c|c|c|c|c|c|c|}
\hline \multirow[b]{2}{*}{ Aft dist. $(L)$} & \multicolumn{6}{|c|}{ Normal propulsion } & \multicolumn{6}{|c|}{ Trailing shaft } & \multirow{2}{*}{$\begin{array}{l}\mathrm{Vo} \\
\mathrm{no}\end{array}$} \\
\hline & 0.00 & 0.07 & 0.21 & 0.50 & 1.00 & 1.601 & 01001 & 0.07 & 0.21 & 0.50 & 1.06 & 1.60 & \\
\hline Centerline & 8 & 10 & 5 & 9 & 6 & 5 & 5 & $\therefore$ & $s$ & 8 & $\therefore$ & 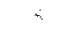 & $\therefore$ \\
\hline $1 / 2$ beam stbd & 5 & 5 & 5 & 5 & 5 & 9 & 5 & $b$ & 5 & 5 & 5 & 3 & \\
\hline $1 / 2$ beam port & 5 & 5 & 5 & 6 & $i$ & 5 & 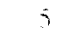 & $b$ & 5 & 5 & 5 & 3 & \\
\hline Totals & 18 & 20 & 15 & 20 & 16 & 19 & 15 & $!:$ & Is & 18 & 15 & 3 & 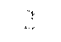 \\
\hline
\end{tabular}

drift runs the targets were scattered randomly within the field-of-view and video taped under fluorescent light.

\section{LAGRANGIAN TRAJECTORY ANALYSIS}

The target trajectories for each run were recorded on color video tape with a black and white, high resolution, low light camera using 625 horizontal lines per screen and $1 / 30 \mathrm{sec}$ between frames. The $x$ and $y$ positions of the center of each visible target in screen pixel dimensions was extracted for every third frame. After an entire run was digitized each individual target trajectory was identified, and the velocity components calculated. All of the data were then transformed into ship coordinates, and nondimensionalized into longitudinal and transverse wake fractions. The coordinate system is provided in Fig. 4. Longitudinal positions $(x)$ indicate ship lengths aft of the model transom. Positive transverse positions $(y)$ indicate ship beams starboard of the model centerline. Velocities indicate fraction of the model speed in the direction of ship motion $\left(W_{x}\right)$ and to starboard $\left(W_{y}\right)$.

The approximate size of the region where the targets fell in ship coordinates was $36.58 \times 2.74 \mathrm{~m}$ in the $x$ and $y$ directions. respectively. For analysis, this region was divided into one-hundred and twenty $0.304 \mathrm{~m}$ long, and nineteen $0.152 \mathrm{~m}$ wide bins. for a total of 2507 bins. The effect of variation in bin size was also investigated. The bin size and number of valid velocity realizations per bin was balanced against the goal of the desired analysis. By reducing the number of bins, there were more points per bin; however, rapid fluctuations in the unsteady velocity components were expected. Similarly, by increasing the number of bins, the spatial frequency response could be increased. However, the spatial frequency of interest in ship generated surface wives

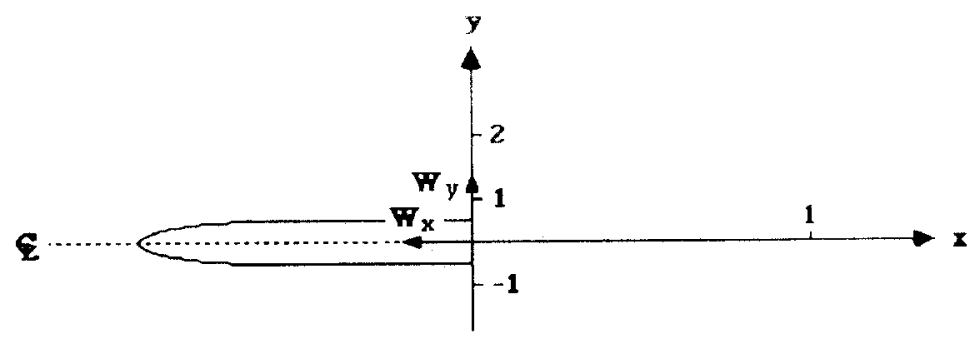

Fig. 4. Coordinate system for trajectory and velocity analysis. 
is generally low, so that the additional computational effort was not warranted. Figure 5 graphically shows the number of targets found in each bin for all runs utilized in this combined analysis.

During a single run at one ship speed, target dropper location, and camera position, targets were released and tracked in a subset of the total wake area, approximately $0.61 \times 12.19 \mathrm{~m}$. Therefore, it was necessary to superimpose data from different dropper locations to fill the $2.74 \times 12.19 \mathrm{~m}$ area behind the ship. Initially, this was done by combining all runs for the largest dropper distance (1.6 ship lengths) and sequentially adding closer dropper distance runs $(1.60,1.00,0.50,0.21,0.07,0.00$ ship lengths). An analysis of the sample mean and variances for each individual bin provided an estimate of the conformation of the dataset to a normally distributed sample. This analysis suggested that leaving all of the points in the data set for analysis would not affect the results. Close examination of the data set revealed that there is a minimum of variation as the additional data are added in sequence; rather, the field becomes increasingly more well defined. This self-consistency also held for the centerline, port and starboard camera and dropper offset positions, but was not so clearly defined between the center, port and starboard data sets. Consequently, these three large data sets were built and it was assumed that any internal errors were random and small. It is possible that the cross-ship variations of ship structure and propulsors influence the cross-ship data set consistency.

The spatial analysis techniques applied to the fluctuating portion of the surface velocity field were carefully chosen. A symmetric, non-recursive, low-pass numerical filter was applied to these data to eliminate phase shifts at the frequencies of interest. The lag window over which the spatial filter is applied is specified in terms of a "cutoff wavelength," $\omega_{c}$. The cut-off wavelength is based on the size of the bins, such that an $\omega_{r}$. of 1.0 implies that all spatial frequencies generating waves of less than 1 bin in length are removed. Recall that the bins are $0.304 \mathrm{~m}$ long and $0.152 \mathrm{~m}$ wide; thus the same cut-off value differs in effect in the transverse and longitudinal directions. Therefore, the lag window was chosen to be just slightly larger than the cut-off wavelength.

With a lag window $(L)$ of 25 bins and a very low cut-off frequency of $\omega_{c}=0.05$ cycles per bin in the longitudinal direction, the filter essentially generates only the mean surface current field (d.c. signal) as shown in Figs 6 and 7. This form of filtering is particularly useful for comparison with full-scale experimental data and numerical modelling estimates.

For a lag window $\left(L_{x}\right)$ of five bins and a higher value of $\omega_{c}=0.35$ in the longitudinal direction combined with a lag $\left(L_{y}\right)$ of four bins and $\omega_{c}=0.45$ in the transverse direction, the center, port, and starboard data can be overlaid to provide a consistent picture of the total velocity field. The resultant matrix of this superposition is shown in Figs 8 and 9. Utilizing this filtering configuration, the longitudinal plane cuts appear essentially unfiltered up to three ship lengths aft. This is displayed in Figs 10 and 11 with transverse plane cuts shown in Figs 12 and 13.

\section{THEORETICAL COMPARISON}

For a theoretical comparison with the longitudinal plane cuts, calculations were made of Kelvin wave patterns in which the phase velocity equals the speed of the ship. The characteristic transverse wave length, $\lambda$, is represented by: 


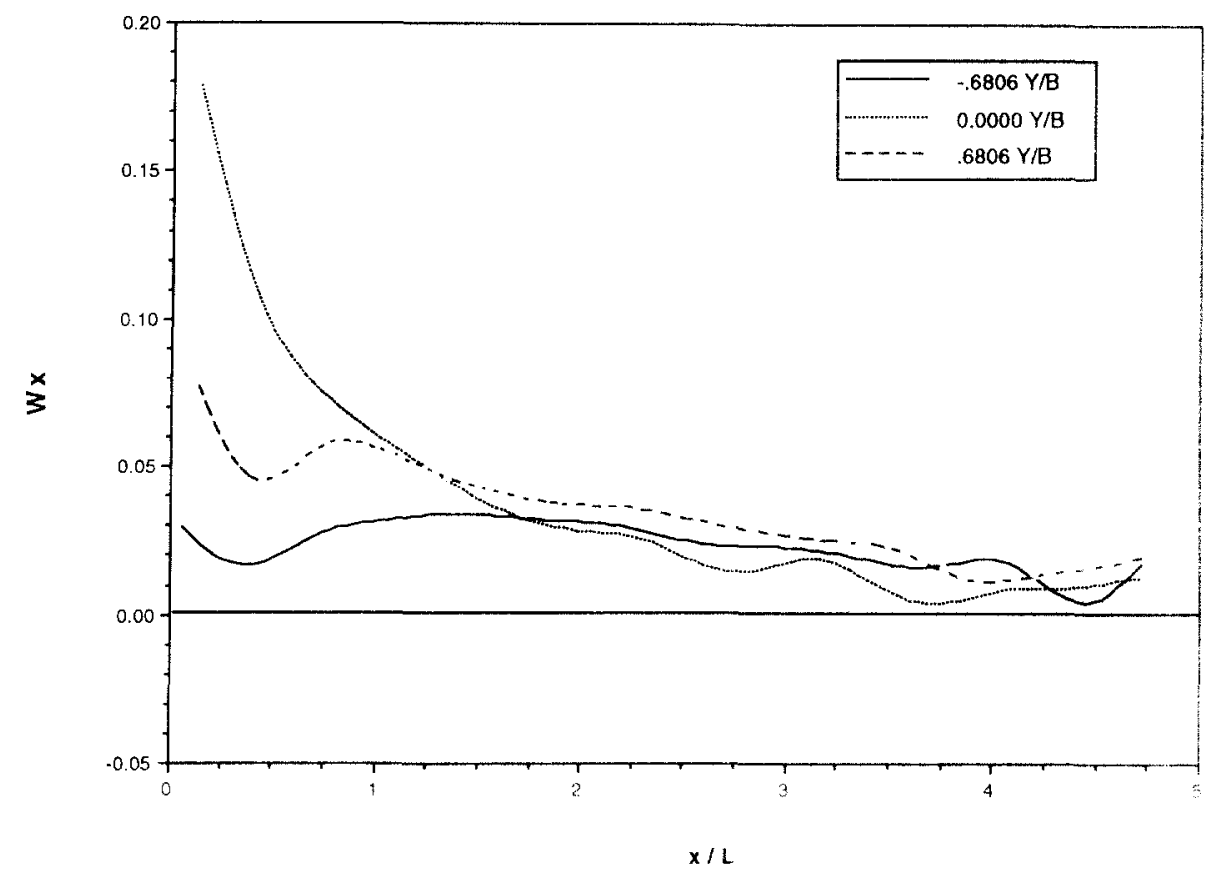

Fig. 6. Downstream surface wake fractions as a function of distance starboard, for longitudinal cuts through wake region, heavy filtering $(\omega=0.05 . L=25)$.

$$
\lambda=2 \cdot \pi \cdot V_{s}^{2} / g
$$

For this case, $V_{s}=2.06 \mathrm{~m} / \mathrm{sec}$, generating a wavelength of $\lambda=2.72 \mathrm{~m}$. Table 2 shows measurements from Fig. 10 that indicate overall agreement with the Kelvin wave pattern. However, the ship generated waves decrease in wavelength with increasing distance downstream.

By modelling the Kelvin wave system as if it was generated by a pressure point located in front of the ship, good agreement is reached with the measured values and the theoretical positions of the first and second wall reflections. For a towing tank with $6.71 \mathrm{~m}$ width, the model should theoretically have the first wall reflection cross the centerline at approximately $8.53 \mathrm{~m}$ and the second reflection about $27.43 \mathrm{~m}$ behind the model stern. Close examination of Fig. 10 shows that the level of variance in the system does indeed increase at those positions.

Tabie 2. Transverse wavelengths measured from Fig. 10

\begin{tabular}{lcc}
\hline Longitudinal position $(x / L)$ & No. of wave orbital cycles & Mean wavelength $(\mathrm{m})$ \\
$(0-1$ & 2.5 & 3.03 \\
$1-2$ & 3 & 2.52 \\
$2-3$ & 3.5 & 2.16 \\
Overall & 9 & 2.52 \\
\hline
\end{tabular}




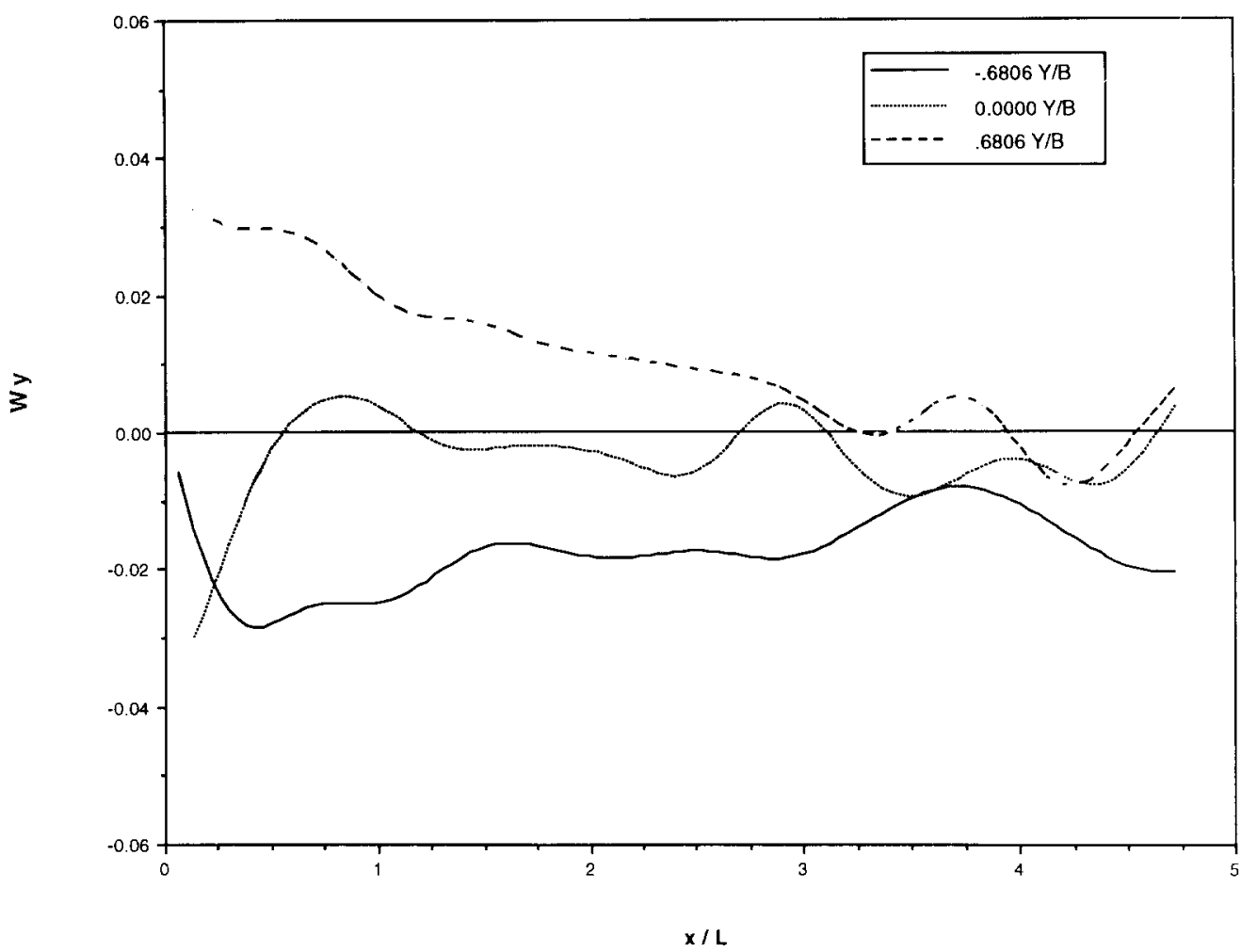

Fig. 7. Cross-stream surface wake fractions as a function of distance starboard, for longitudinal cuts through wake region, heavy filtering $(\omega=0.05, L=25)$.

\section{HYDRODYNAMIC INSIGHTS}

The asymmetry of $W_{x}$ and $W_{y}$ shows a greater axial velocity at the free surface on the port side and higher transverse velocities than the starboard side. The near-field peak at $x=3.05 \mathrm{~m}$ is at $y=0.152 \mathrm{~m}$ rather than at the centerline in Fig. 8 and $W_{y}=+0.04$ for starboard and -0.035 for port at $x=3.05 \mathrm{~m}$ in Fig. 9 . One possible explanation for this asymmetry is that the thrust wake from the shallower set shaft angle of the port propeller provides a visible contribution to the surface flow field in the near wake.

Based on the appearance of wave orbital velocities in the dataset, measurements of transverse wavelength were made. The average transverse wave length of $\lambda=2.52 \mathrm{~m}$ (see Table 2) is within $8 \%$ of that predicted by a theoretical Kelvin pressure point wave system at $V=2.06 \mathrm{~m} / \mathrm{sec}$. This corresponds to the wavelength found at $x / L=0.9$.

There is clear evidence of the wave reflections based on some increase in the noise of the system and comparison with pressure point Kelvin wave generation, but this does not appear to affect the oscillations of the ship wake patterns. Therefore, surface waves must have an effect on the surface wake. Indeed, an assumption of linear independence seems justified.

By combining both $x$ and $y$ velocities on one graph, the effects of surface vorticity 


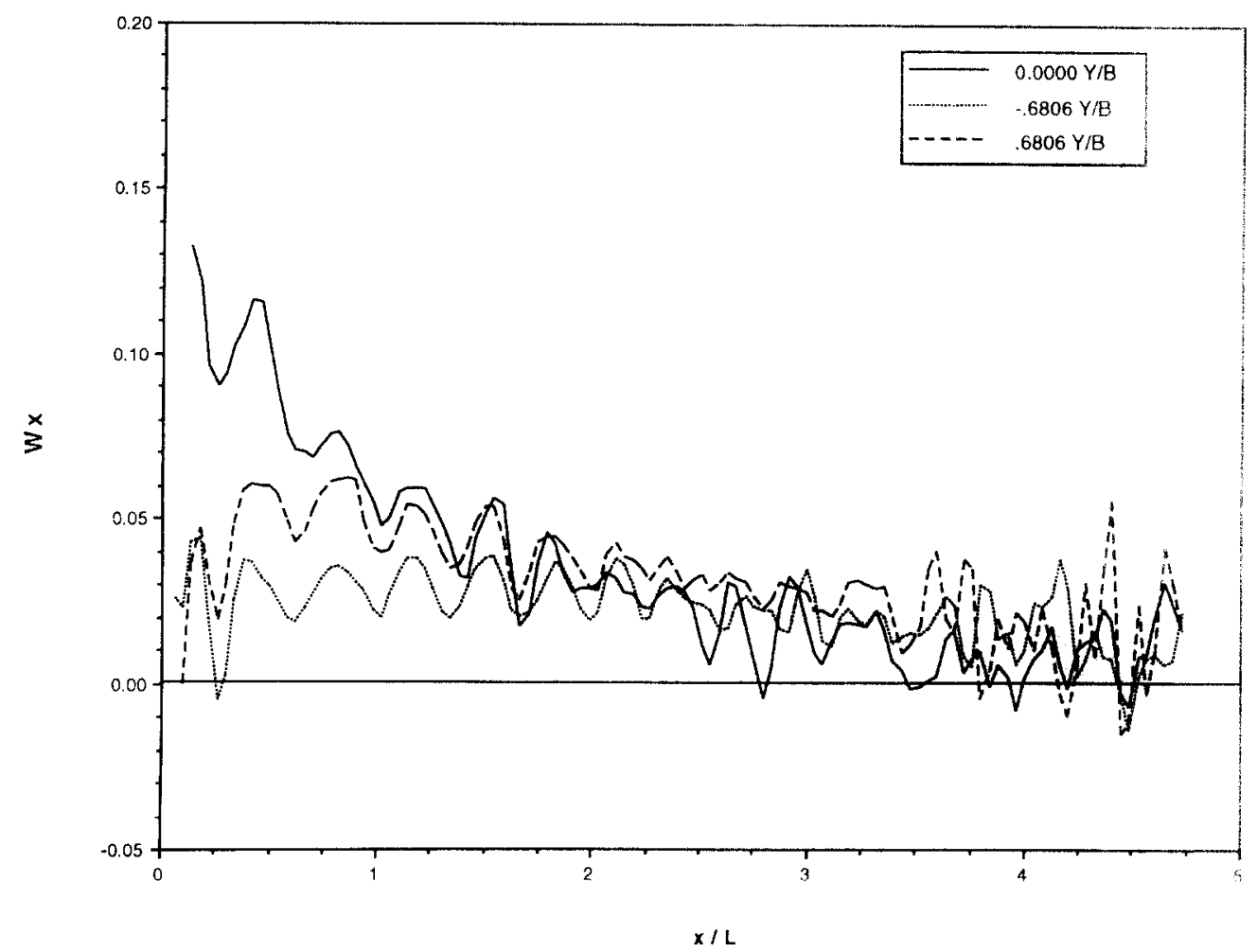

FIG. 10. Downstream surface wake fractions as a function of distance starboard, for longitudinal cuts through Fig. 8, light filtering $\left(\omega_{x}=0.35, L_{x}=5, \omega_{y}=0.45 . L_{y}=4\right)$.

may be examined. Figure 14 is a unit vector diagram expressing velocity magnitude by color. Note that the velocities in both directions are very small far downstream but the vectors retain their unit length. A significant pattern can be seen in which every three or four bins have either purely longitudinal or purely transverse velocities along the edge. This gives evidence for sustained vorticity at the edges of the flow field. Figures 15 and 16 are two-dimensional plots of $W_{x}$ and $W_{y}$, respectively, which may help in visualizing the two velocity fields.

A regression was performed on the downstream rate of decay of both the mean longitudinal and transverse velocity components. The spatial rates of decay of these surface velocity signatures were fit to a general expression of the form

$$
W_{i}=a\left(\frac{X}{L}\right)^{b}
$$

where $W_{i}$ is the corresponding wake fraction in the $x$ and $y$ directions, respectively, $L$ is the ship length and $a$ and $b$ are regression coefficients.

The downstream rate of decay was best fit by

$$
a=0.0540
$$




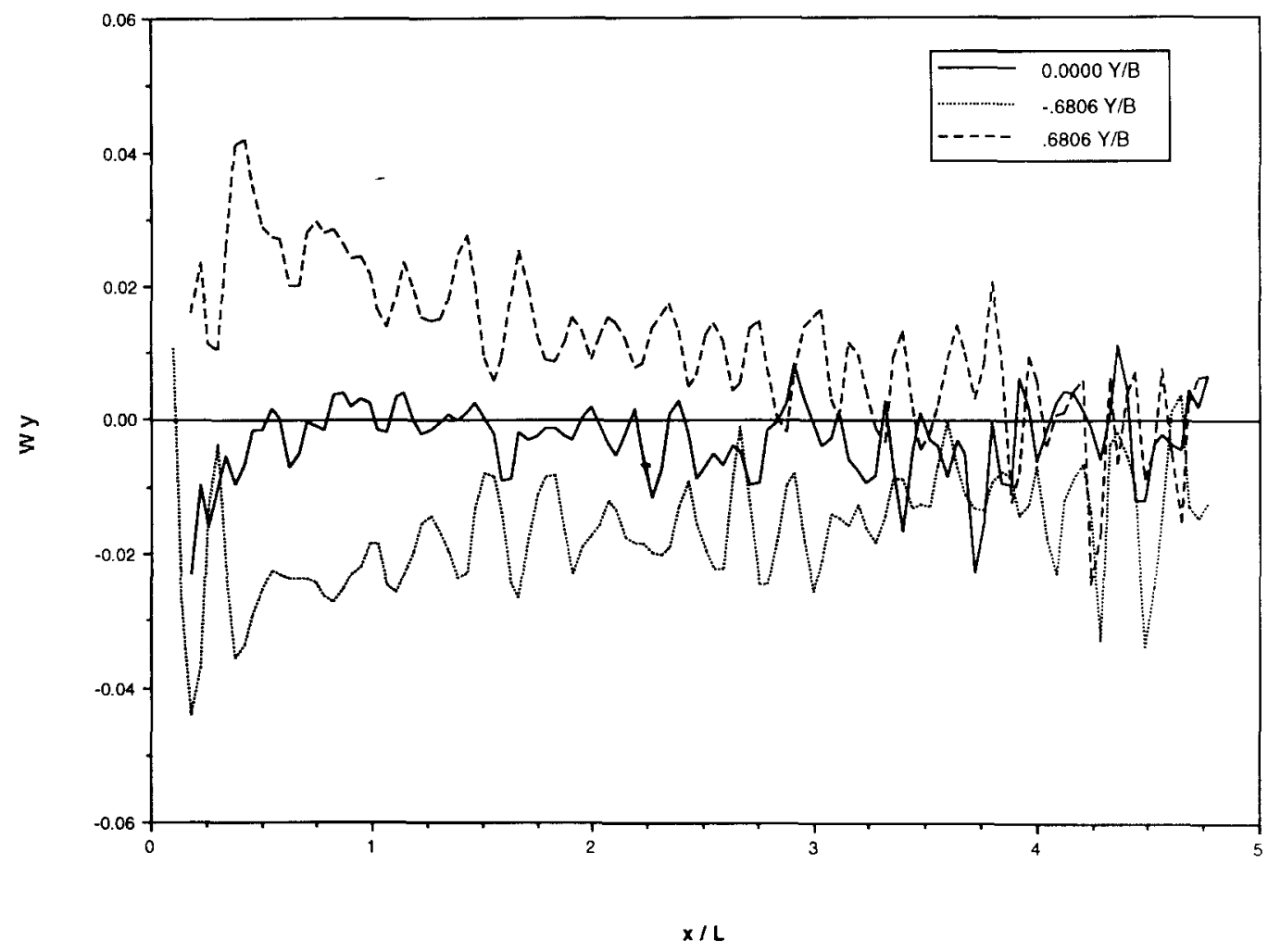

Fig. 11. Cross-stream surface wake fractions as a function of distance starboard, for longitudinal cuts through Fig. 9, light filtering $\left(\omega_{x}=0.35, L_{x}=5, \omega_{y}=0.45, L_{y}=4\right)$.

and

$$
b=-0.921
$$

with a correlation coefficient of $r=0.98$.

Similarly, the rate of decay of the cross-stream velocity with distance aft was best fit by

$$
\begin{aligned}
& a=0.0195 \\
& b=-1.203
\end{aligned}
$$

with a correlation coefficient of $r=0.94$.

\section{COMPARISON WITH FULL-SCALE AND NUMERICAL MODEL RESULTS}

\section{Full-scale measurements}

Results of the model scale experiment were compared with full-scale measurements obtained as part of the ONR Ship Wake Experiment. This program was a field test activity designed to develop quantitative descriptions of the hydrodynamic wakes of surface ships (Chapman, 1989).

The test operations took place on the Pacific Missile Test Center (PMTC) range 


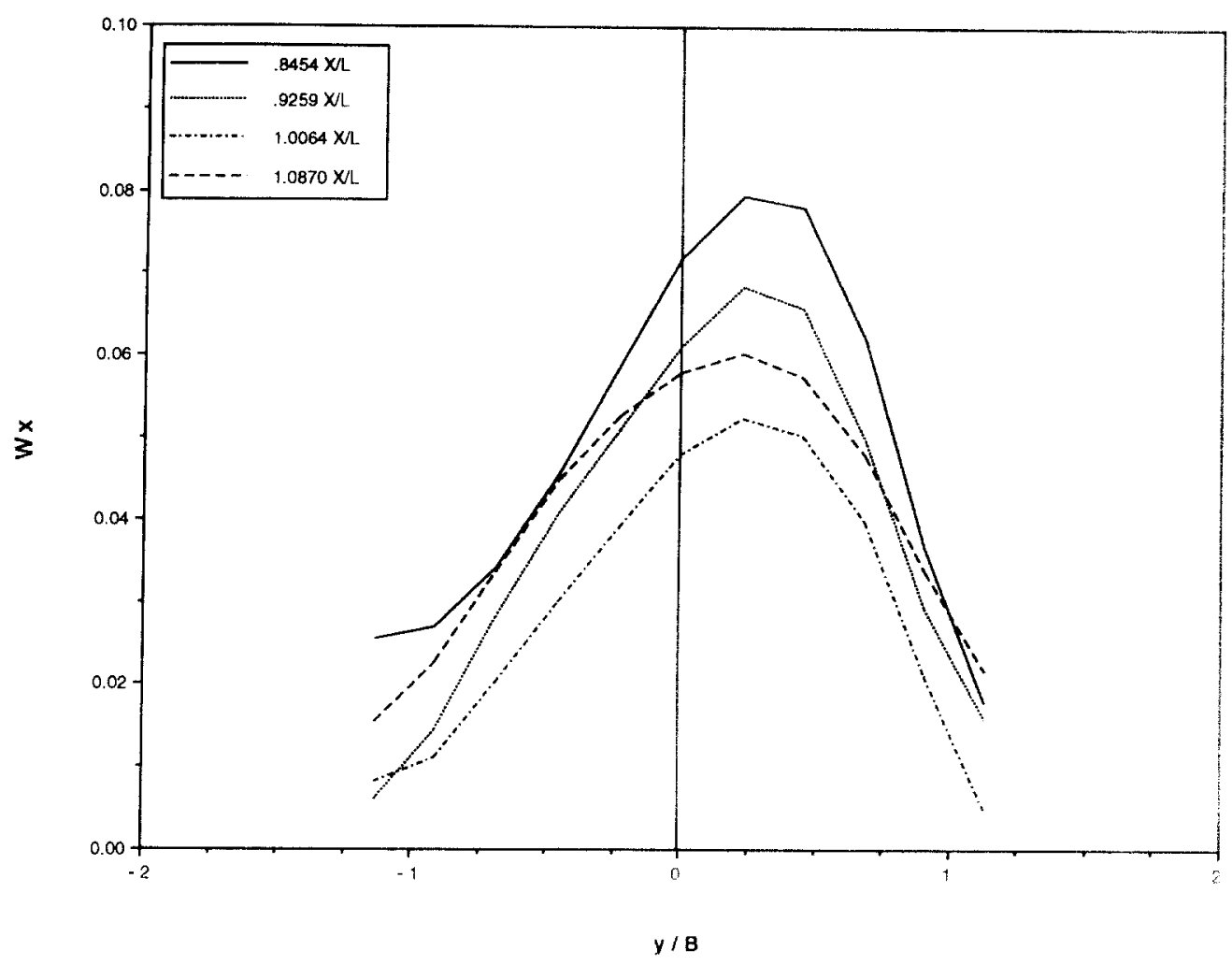

Fig. 12. Downstream surface wake fractions as a function of distance starboard, for transverse cuts through Fig. 8, light filtering $\left(\omega_{x}=0.35, L_{x}=5, \omega_{y}=0.45 . L_{v}=4\right)$.

near Santa Cruz Island, off the southern California coast. In total, seven U.S. Navy ships served as target vessels for the experiment. During selected runs, a helicopter dropped surface drifters into the wake to measure wake velocities. The drifters were tracked with the helicopter's camera systems and platform motions were recorded digitally. After placing the surface drifters in the wake, the helicopter was held in a high hover at a predetermined altitude (sufficiently high to produce no visible surface disturbance from helicopter rotor wash) for surface drifter imaging. Since these drifters are readily seen on the video images, their positions were sequentially tracked to determine the large-scale, time-averaged velocities in the longitudinal and transverse directions in a manner similar to the DARTS model scale analysis previously described.

The helicopter filming platform provided one more level of complexity not present in the model scale analysis. Several geometric corrections needed to be made to adjust for the high-frequency, small-scale motions of the helicopter, the oblique angle of the video camera in the helicopter relative to the true position of the drifters, and any low-frequency, large-scale trends in the orientation and position of the helicopter. These corrections are mainly a result of helicopter attitude (pitch, roll, and yaw) and altitude. The helicopter's velocity, pitch, roll, yaw (heading), position (latitude and longitude), and altitude were all recorded by instruments on the helicopter at a frequency of $10 \mathrm{~Hz}$, or by PMTC. Once these three-dimensional geometric corrections 


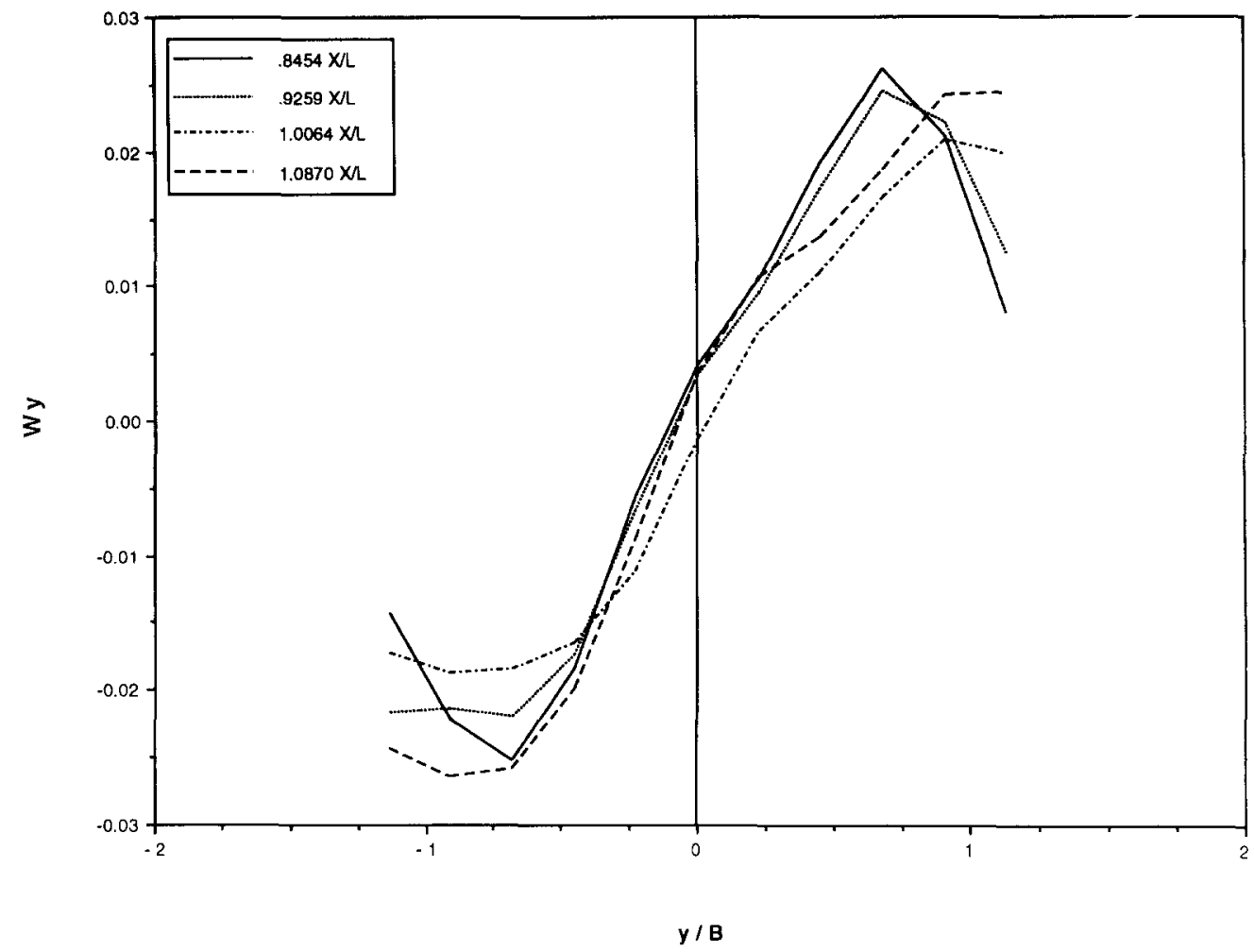

Fig. 13. Cross-stream surface wake fractions as a function of distance starboard, for transverse cuts through Fig. 9, light filtering $\left(\omega_{x}=0.35, L_{x}=5, \omega_{y}=0.45, L_{y}=4\right)$.

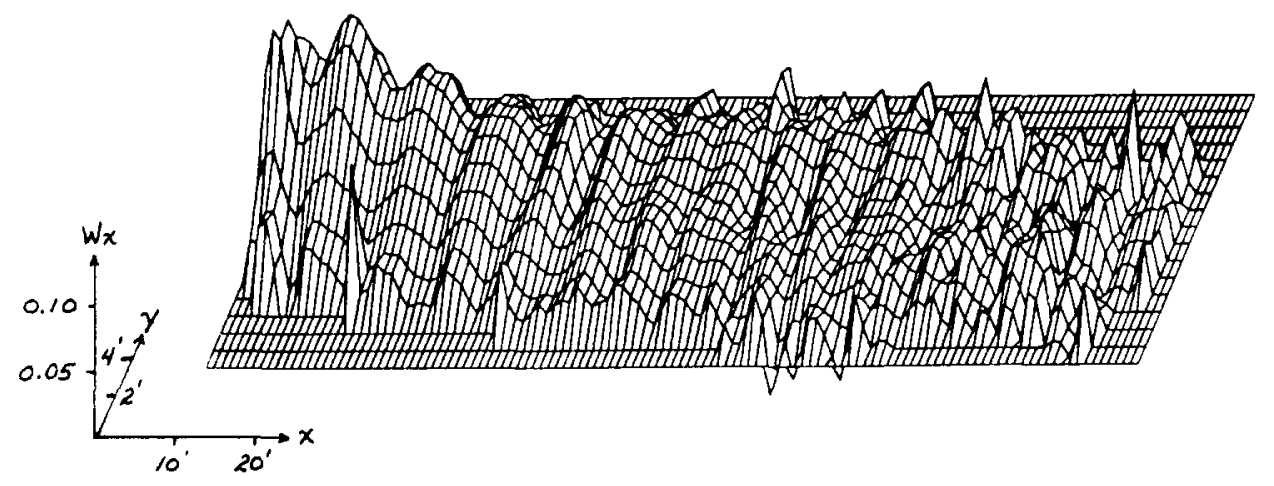

FIG. 15. Two-dimensional plot of $W_{x}$.

are made, then the digitized position of the surface drifters are referenced to the same global coordinate system and the distance traveled per unit time can then be analyzed on a frame-by-frame basis. Analysis of the data was then performed for periods of the experiment during which helicopter motion was relatively stable. The results for a 


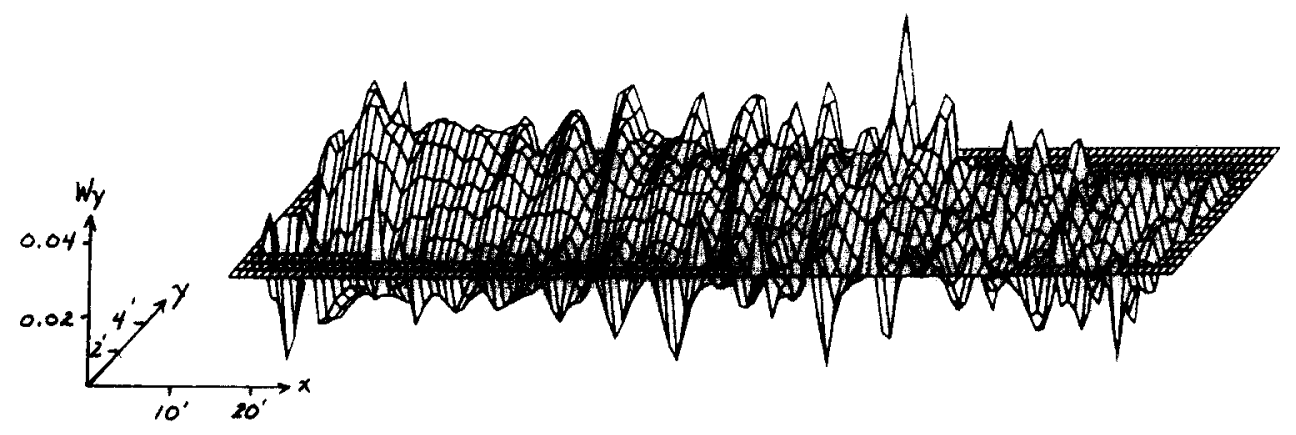

Fic. 16. Two-dimensional plot of $W$,

similar class vessel operated at a similar speed are provided in Fig. 20, for comparison with model scale results, as well as numerical modelling calculations.

\section{Numerical modelling}

The present state-of-the-art model for predicting the turbulent wakes of surface ships is represented by the steady and parabolic, incompressible, time-averaged Navier-Stokes equations together with a two-equation (kappa, epsilon) model for turbulence closure. The TWAKE computer code based on these equations was developed at NRL (Swean, 1987) for the purpose of computing the propagation of the turbulent wake in proximity to a free surface. The NRL code TWAKE is a suitably modified derivative of the three-dimensional parabolic Navier-Stokes (3DPNS) finiteelement code originally developed by Baker (1983). The parabolic nature of the numerical model requires a set of initial data in order to begin a computation. These data include the three components of mean velocity, the turbulence kinetic energy, and the turbulence dissipation function. For the case of the surface ship wake the initial plane is derived most effectively from experimental data, though very few data sets of sufficiently high resolution are available.

The model test data employed in the recent computations by Swean (1987) were obtained from the David Taylor Research Center towing basin tests of a high speed combatant model that is similar to the model employed in the present experiments. The model and test conditions as they relate to the computations are summarized in Table 3. Mean velocities, RMS turbulence intensities, and the Reynolds stresses were

TABle 3. TWIN SCREW HIGH SPEED COMBATANT PARAMETERS (1:25 SCALE)

\begin{tabular}{lc}
\hline \multicolumn{1}{c}{ Model: high speed combatant; DNTSRCS No. 5415-01 } \\
Length* & $18.8 \mathrm{ft}(5.73 \mathrm{~m})$ \\
Beam & 29.9 in. $(0.76 \mathrm{~m})$ \\
Draft & 9.8 in. $(0.25 \mathrm{~m})$ \\
Propeller diameter & $8.16 \mathrm{in} .(0.21 \mathrm{~m})$ \\
Block coefficient & 0.506 \\
& $4.0 \mathrm{kn} .(2.04 \mathrm{~m} / \mathrm{sec})$ \\
Tow speed & 0.28 \\
\hline
\end{tabular}

* Length between forward and aft perpendiculars. 
obtained at several planes aft of the model using a system consisting of three component Laser-Doppler Anemometer (LDA) and a hot-film anemometer array.

These data were subsequently employed in a numerical simulation of the downstream evolution of the model's turbulent wake. The initial plane of the calculation was located four ship beams $(x / B=4)$ aft of the stern. A contour plot in the $y-z$ plane of the downstream ( $x$-direction) mean velocity at this location is shown in Fig. 17, for the experiments with outboard propellor rotation. These contours represent an interpolation of the experimental data directly to the computational grid. The calculation extended downstream to approximately 1000 ship beams $(x / B=1000)$ aft. The study conducted by Swean (1987) includes extensive comparisons between the computations and the DTRC model-scale test data for all experimentally measured quantities. The good agreement realized in that analysis gives some confidence toward making further comparisons with field experiments and other model tests.

A contour plot of the surface $(x-y)$ plane distribution of the mean velocity difference $\Delta u$ in the $x$-direction is shown in Fig. 18, where the downstream and cross-stream distances are scaled by the ship beam, $B$. The computed results show that the mean surface features of the wake decay rapidly. The mean surface wake flow is greatly diminished at 12 ship beams $(x / B=12)$ downstream. This distance corresponds to approximately 1.6 ship lengths. In the far wake the propeller thrust has broached the surface at 10 ship beams $(x / B=10)$ aft and displaces the drag wake outboard.

A comparable representation of the wake half-width $d$ at 500 ship beams $(x / B=500)$ downstream in Fig. 18 is $d / B=1.25$ when the $W_{x}=0$ contour is employed there to define the cross-track extent of the surface wake. This downstream distance is approximately half of the wake width which is typically measured from aerial photographs of the "visible white water" wake of a surface ship (Peltzer, 1984). This downstream

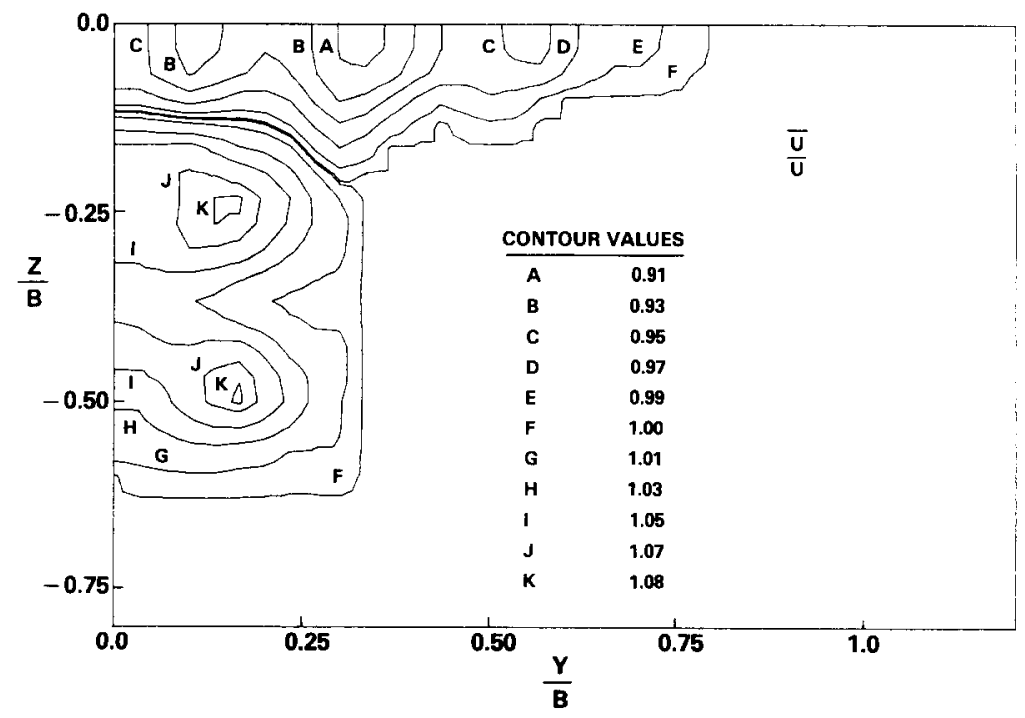

FIG. 17. The initial $(y, z)$ mean velocity plane for the calculation of the high speed combatant model wake. The initial plane is at four ship beams $(x / B=4)$ aft and the propeller rotation is outboard; from Swean (1987) 


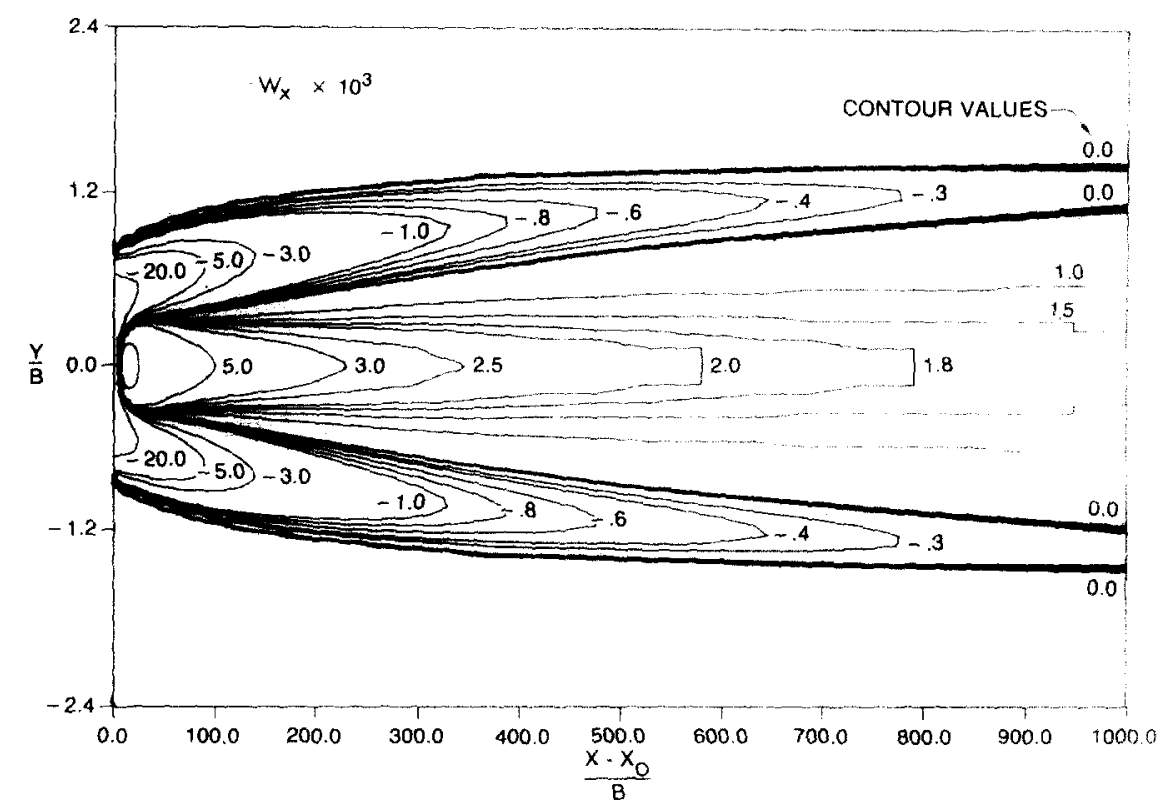

FIG. 18. A contour plot of the surface $(x, y)$ plane distribution of calculated mean velocity $W$, from the high speed combatant wake. Conditions as in Fig. 17; from Swean (1987).

distance is equivalent to 66 ship lengths $(x / L=66)$ for the high speed combatant model with $B / L=0.133$.

Three longitudinal cuts of the surface mean velocity were made along the wake centerline and at two offset locations of $y / B=0.60$ and 0.67 . The latter closely match the offset location of $y / B=0.68$ from the high speed combatant model experiments. Only the positions on the positive (starboard) side were used since the calculated ship wake is symmetric about the wake centerline. These two longitudinal cuts are plotted in Fig. 19(a), and show substantial differences in the early wake even though they are displaced only slightly in the cross-wake direction. This follows from the shape of the contours of constant surface mean velocity in the early wake that are shown in Fig. 18 . Both of the longitudinal cuts remain in the drag or positive $W_{x}$ portion of the surface wake over the downstream distance of 1000 ship beams $(1000 B)$ from the initial plane that is shown in Fig. 17. These same two longitudinal cuts are plotted with downstream distance on a logarithmic scale in Fig. 19 (b) in order to highlight the early wake flow. The cuts in Fig. 19(a) and (b) extend over the full distance of 1000 ship beams aft that is shown in the contour plot of Fig. 18.

\section{COMPARISON: MODEL SCALE VS FULL-SCALE VS NUMERICAL MODELLING}

Figure 20 contains the downstream evolutions of the surface mean velocity tractions for each of the three longitudinal cuts $(y / B=-2 / 3,0.2 / 3$, approximately $)$ as obtained from the UM model tests, the full-scale experiments, and the NRL computations. The operating Froude numbers, $F r=V / \sqrt{(\mathbf{g} L)}$, and the aspect ratios, $A R=B / L$, of each of the vessels represented in the three cases are similar, being $(F r, A R)=(0.23,0.088$; 


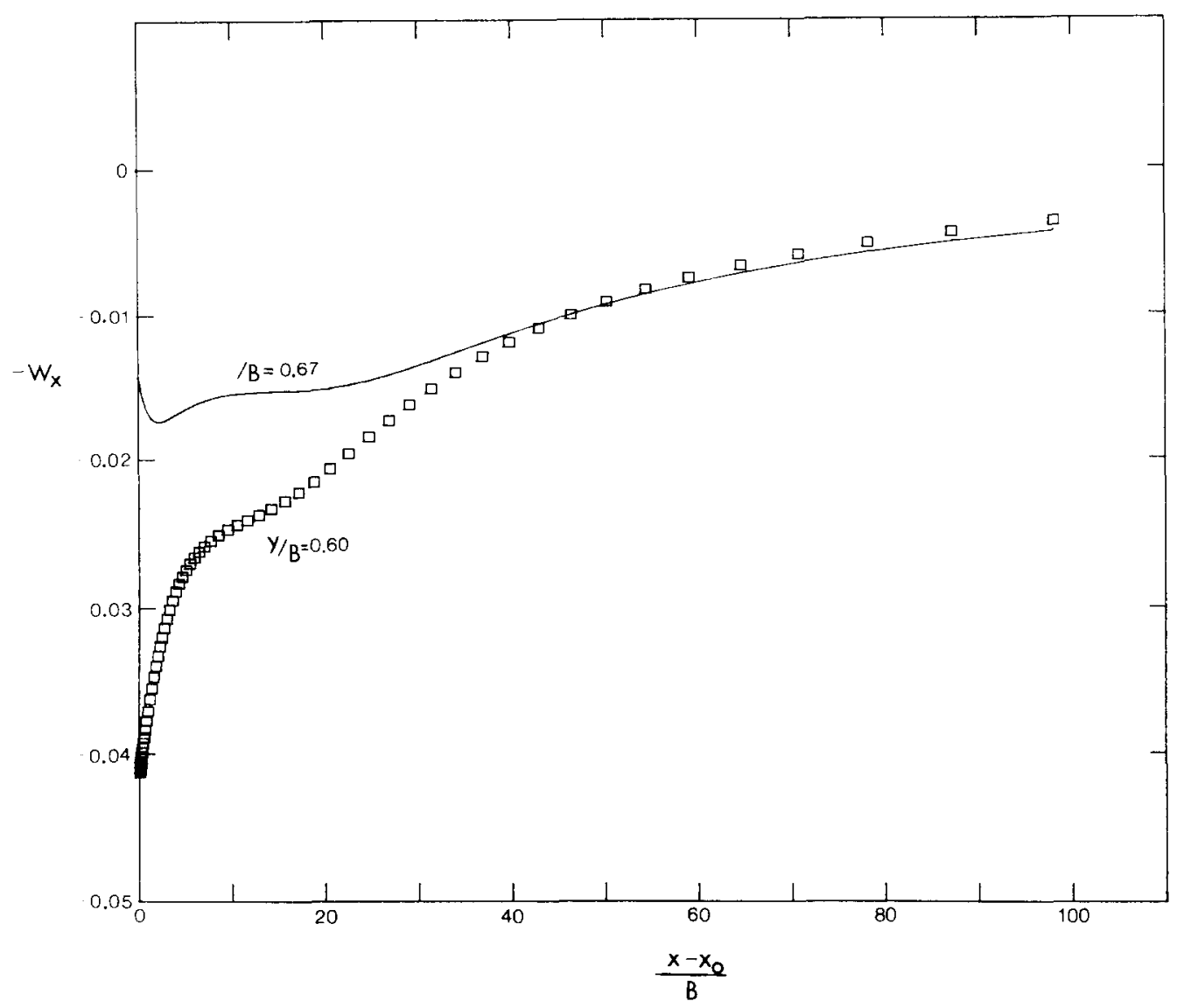

FIG. 19 (a). Longitudinal plane cuts of the calculated plane mean velocity $W_{x}$ from the high speed combatant wake. Conditions as in Fig. 17.

$0.23,0.104 ; 0.28,0.133)$, respectively. The Reynolds numbers $\left(R e=V^{*} B / v\right)$ for the three cases, however, are quite different, being $1.36 \times 10^{6}, 1.53 \times 10^{8}$, and $1.49 \times 10^{6}$, respectively. The overall agreement between the data sets is encouraging given the range of $R e$ that pertain to the three. The physical experiments show asymmetry in the off-centerline cuts for reasons already mentioned, while the computations were constrained by symmetry boundary conditions. Both the model test data and the numerical data [see also Fig. 19(a)] show the same qualitative behavior in the very near wake, each containing a minimum in the velocity decay very near the origin for the off-centerline cuts. The full-scale data do not extend as close to the vessel in units of $x / L$, but the data suggest that a minimum was in existence near $x / L=0.5$. The scatter in the full-scale data prevent definitive comments regarding the rate of decay of the velocity for that case, but it is apparent that the decay rates are progressively higher from full-scale data to model-scale data to simulation data.

The rate of decay is very sensitive to the initial turbulence level and the rate of dissipation of turbulence. The computations (Swean, 1987) made use of measured values of turbulence kinetic energy and Reynolds shear stresses to initialize the dissipation rate 


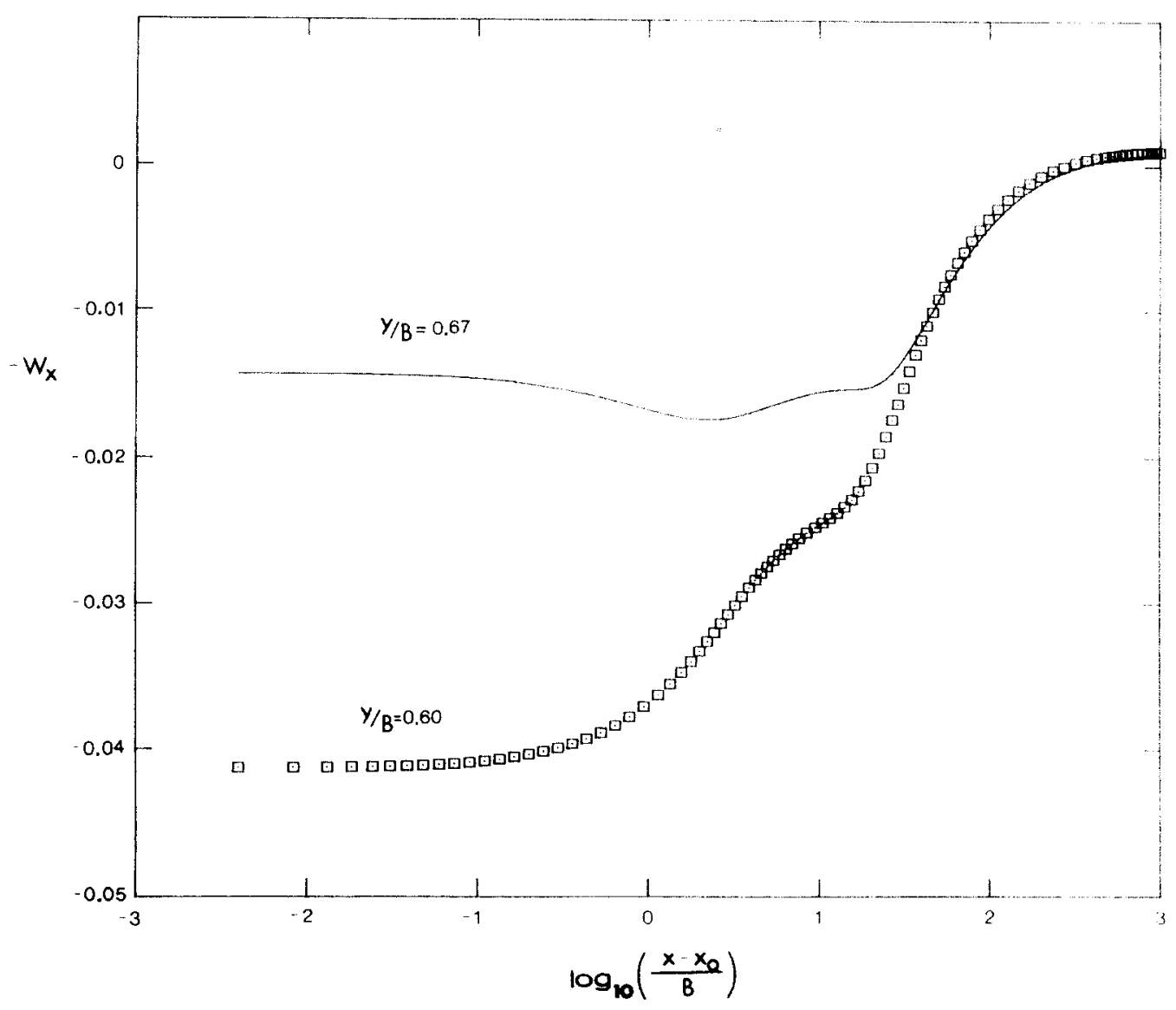

FIG. 19 (b). Longitudinal plane cuts of the calculated surface plane mean velocity $W_{x}$ from the high speed combatant wake. The horizontal axis (dist. aft) is in logarithmic form to emphasize the early wake. Conditions as in Fig. 17.

consistent with the Boussinesq eddy viscosity mode. This procedure yielded excellent agreement between computation and experiment for velocity decay in the near wake. Unfortunately, the present experiments did not obtain sufficient data to estimate these quantities, and so it is not possible to fully understand the differences in the current data with respect to the decay rates.

\section{CONCLUSIONS}

The following conclusions are drawn as a result of this investigation and subsequent detailed analysis of the composite data sets collected (approximately 30,000 velocity observations in the near wake region).

With respect to the method of surface wake velocity measurement acquisition, this procedure was proven highly accurate and repeatable. The level of error in digitizing target positions was less than $1 \%$ of the wake coverage. The use of 15 targets per run was sufficient to provide an even distribution of velocity measurements throughout the 


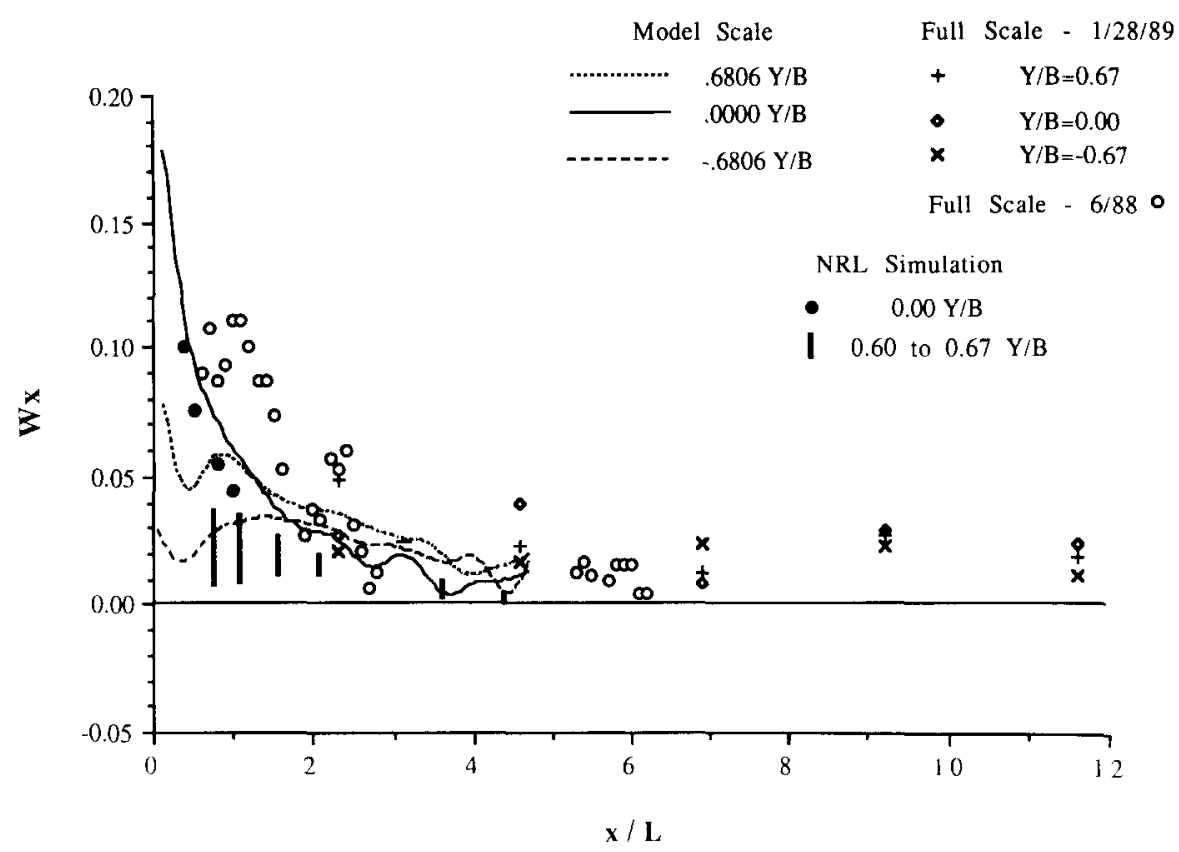

Fig. 20. Comparison of model scale, full-scale and numerical model simulations of longitudinal surface velocities in the wake of a high speed vessel.

wake field up to $27.43 \mathrm{~m}$ aft. The analysis could have extended farther downstream with careful removal of inherent wall reflections with little loss of overall data quality.

Statistically, the numbers of individual velocities in each bin that exceeded three standard deviations from the bin mean velocity were less than $1 \%$ of the total number of points digitized and accepted. This is consistent with minimum standards for a normally distributed ensemble. Within each offset dataset (port and starboard), repeated runs of the same conditions are virtually identical. Runs with offset port or starboard positions required only light filtering for excellent agreement. Numerical filtering of the final data set proved to be an effective tool in data analysis, providing insight into the hydrodynamics influencing the surface wake velocities.

This method of data acquisition, reduction and analysis is sensitive enough to clearly show the orbital velocity influence of the Kelvin wave pattern, identification of the tank wall reflection, and a surface wake perturbation possibly due to hull and propeller asymmetry. In addition, it has been shown that the DARTS system can determine surface velocity vectors and can be used to detect and quantify vorticity in the wake (i.e. the rate of change of velocity in aspect to position or $\frac{\partial V_{y}}{\partial_{x}}-\frac{\partial V_{x}}{\partial_{y}}$ ) if the analysis is performed in a fixed inertial reference frame.

In addition, there is good agreement between the model scale experiments, the numerical wake calculations, and the full-scale field experiments. This is quite remarkable given the range of scales from the model and the calculated wake (both approximately 1:25) to the field. The presence in the near wake region of relatively strong 
diverging surface currents (from the center outward) is well characterized by these observations. This flow structure is coherent over the length of the test and shows a slow decay with distance aft of the form:

$$
W_{x}=0.054\left(\begin{array}{l}
X \\
L
\end{array}\right)^{-0.921}
$$

Finally, extraction of all of the information generated by this technique has not yet been exhausted, but requires additional detailed analysis. The apparent quality of the data set, however, strongly suggests that this analysis will produce extremely fruitful results and may aid in the interpretation of remotely sensed surface ship wake signatures.

Acknowledgements-This investigation was sponsored by the David Taylor Research Center (DTRC) under contract to the Department of Naval Architecture and Marine Engineering, Program in Ship Hydrodynamics (PSH), College of Engineering. The University of Michigan, and by the Office of Naval Research, Surface Ship Wake Detection Program

\section{REFERENCES}

Baker, A.J. 1983. Finite Element Computational Fluid Mechanics. McGraw Hill/Hemisphere. New York. ChAPMAN, R.D. 1989. ONR ship wake experiment operations summary. Johns Hopkins University Applied Physics Laboratory, Report No. JHU/APL STD-N-609.

Griffin, O.M., Skop, R.A., Keramidas, G.A. Swean, T.F. Jr. Wang. H.T. and Leipol.d, Y. 1989. Ocean and ship wave modification by a surface wake flow pattern. Proceedings of the Seventeenth ONR Symposium on Naval Hydrodynamics, pp. 17-38. National Academy Press, Washington, D.C

Lindenmuth, W.T. 1986. Private communication: data from the Model 5415 experiment at the David Taylor Research Center.

Meadows, G.A., Lyzenga, D., Lyden, J. and Beck, R. 1990. Nonintrusive, multiple-point measurements of water surface slope, elevation and velocity. Proceedings of the Eighteenth ONR Symposium on Naval Hydrodynamics, pp. 349-360. National Academy Press, Washington. D.C.

Meadows, G.A., Meadows, L.A., Weishar, L.L. and Fiel.ds, M.L. 1988. DARTS (Digital Automated Radar Tracking System): application to tidal inlet hydrodynamic studies. In Lecture Notes on Coastal and Estuarine Studies, Vol. 29, pp. 167-185. Springer, Berlin.

Meadows, L.A., Meadows, G.A., Troesch, A., Cohen, S., Beier, K.P., Beck, R. and Reed, A. 1989. Lagrangian velocity profiles in the wake of a high speed vessel. University of Michigan Program in Ship Hydrodynamics Report, Ann Arbor, Michigan (26 pp.).

Reed, A.M., Beck, R.F., Griffin, O.M. and Peltzer. R.D. 1990. Hydrodynamics of remotely sensed surface ship wakes. SNAME Trans. 98, 319-363.

Skop, R.A., Griffin, O.M., Swean, T.F. JR and Nicolas, K.R. 1989. Modification of wave spectra by currents in the wake of a surface ship. Naval Research Laboratory Memorandum Report 6336

SWEAN, T.F. JR 1987. Numerical simulations of the wake downstream of a twin-screw destroyer inodel Naval Research Laboratory Memorandum Report 6131 